\title{
Between the Virtual and a Hard Place: The dilemma of digital art museums
}

\author{
Helena Barranha \\ CERIS, Instituto Superior Técnico, \\ Universidade de Lisboa \\ Av. Rovisco Pais, 1 \\ 1049-001 Lisboa, Portugal \\ helenabarranha@tecnico.ulisboa.pt
}

\begin{abstract}
During the last two decades, the emergence of fresh categories within new media art has posed unprecedented challenges to museums, motivating the creation of new institutions specifically designed to house and display works of this type. Therefore, digital and Internet art have configured an interesting field for architectural research. Frequently, the architecture of these new museums has revealed utopian visions that derive from profound contradictions between the intangible world of communication technology and the conventional requirements of physical spaces. Just as in previous periods of art history, some of the most ground-breaking projects did not end up as finished buildings, either because their construction would be too expensive and technically problematic, or just because they were deliberately conceived as virtual spaces. However, and surprisingly enough, even these web-specific museums sometimes proved to be too ambitious or ahead of their time. In this scenario, and drawing on a set of emblematic projects, this paper seeks to discuss a topical question: how can museum architecture deal with the intangible, unstable and ubiquitous condition of digital art?
\end{abstract}

Digital art. New media art. Post-Internet culture. Museum architecture. Virtual museums.

\section{INTRODUCTION}

In his video installation "Between Cinema and a Hard Place" (1991), the American artist Gary Hill proposed a reflection on the relationship between cinematic space and real space, which would subsequently be expanded and re-contextualised in 2000, when Tate Modern presented an exhibition with the same title (Tate 2000). This subject-matter can also be transposed to the broader context of new media art, since Garry Hill's work introduces a wide range of questions on material and intangible features of contemporary culture, involving both the artwork and the exhibition space.

Over the last two decades, the increasing pervasiveness of digital systems has emphasised the complexity of new media art, namely with the dissemination of immaterial networked contents and the corresponding new artistic categories, such as digital or Internet art. Consequently, art institutions, curators and the artists themselves are now confronted with an unprecedented dilemma: should these works be shown in the physical space of the museum gallery, or exclusively online? (Morris 2001, p. 12). Considering that most digital and web artworks are actually more likely to be found outside institutional spaces, can the digital art museum still be regarded as a 'building', or has it completely lost its walls in favour of an intense and uncertain network circulation that takes place somewhere else? (Barranha et al. 2015).

In this scenario, the architectural conceptualisation of digital art museums soon revealed its contradictions. In his influential essay "The Museum of the Third Kind" (1996), Roy Ascott pointed out that the term 'digital museum' is in itself an "oxymoron since 'digital' speaks of fluidity, transience, immateriality and transformation, while 'museum' [...] has always stood for solidity, stability, and permanence". In response to this apparent paradox, a twofold approach to museum design has been developed since the 1990s: on the one hand, virtual exhibition spaces have emerged and multiplied on the Internet as a democratic and exciting alternative to traditional institutions; on the other hand, physical galleries have also been redesigned in order to accommodate new media artworks. 
More recently, the globalisation of communication technologies and social media has paved the way for a growing convergence of material and virtual dimensions. In this context, which Marisa Olson has described as Post-Internet, as it "encompasses and transcends new media" (Olson 2011, p. 215), the architecture of digital art museums has evolved towards new forms of hybridisation, incorporating both tangible and virtual elements. Drawing on pioneering experiments that date back to the 1970s, the electronic façade has been reinvented as a powerful urban, architectural and curatorial device. Interacting with virtual and augmented reality, it became an important device for architectural, artistic and curatorial research. Moreover, it soon came to be a metaphor of transformation and connectivity, two fundamental values for contemporary society. Although the most radical projects have remained unbuilt, they have paved the way for new paradigms in the architecture of new media and digital art museums.

Through the analysis of representative (yet not always successful) projects from the last two decades, this paper seeks to discuss a topical question: how can museum architecture deal with the intangible, unstable and ubiquitous condition of digital art?

\section{NEW MEDIA ART AND MUSEUM ARCHITECTURE}

The history of museum architecture has always expressed the relationship between container and contents, and therefore some of the most emblematic examples of this building type clearly reflect the specific nature of the collections they are supposed to house and display. New media artworks are no exception to this principle, even if these contents inevitably entail a higher degree of unpredictability. In this sense, the emergence of new media art as a new curatorial field is also crucial to understanding the evolution of museum architecture.

Since its origins in the mid-twentieth century, new media art has proved to be a complex and uncertain territory. Based on technological systems that, despite their common dependence on electrical power, are extraordinarily variable, media art poses some very specific issues in terms of reproducibility and authorship, access and digital protocols, updating and obsolescence, preservation and loss. According to Electronic Arts Intermix, a leading institution in this area:

\footnotetext{
Nearly four decades after video art was first screened in alternative spaces, media-based artworks and installations are ubiquitous in museums and galleries. Artists are creating media artworks for exhibition contexts ranging
}

from black box cinemas and white cube galleries to Web sites and iPods. The boundaries between single-channel video, computer-based art and media installations continue to blur and evolve. A media artwork may have multiple iterations. Artistic practices drive new exhibition modes, from display equipment and formats to issues of audience interaction and access. (EIA 2013)

This conceptual and technological evolution of artistic production has raised entirely new challenges for cultural institutions dealing with the conservation, documentation and exhibition of such works. In fact, the radical changes that media art has brought about have affected not only artistic and curatorial practices, but also the role of audiences, and their interaction with the gallery space. Furthermore, the commercialisation of the first personal computers, in the 1980s, has opened up new artistic perspectives. Since then, and mainly after the globalisation of Internet access, digital technology has reshaped all aspects of contemporary culture, and eventually configured a new category - digital art - in which it appears "in any of three ways: as the product, as the process, or as the subject" (AMODA 2016). Gradually, the development of new artistic practices along with the updating of previous disciplines (such as photography or video, for instance) has redefined the notion of new media art and, as Christian Paul points out, "in the early twenty-first century, the term 'new media' is mostly used for digital arts in its various forms" (Paul 2002, p. 471). Following this observation, this paper adopts an all-embracing definition of digital art, making no significant distinction between new media and digital art museums.

At the same time, the idea of the museum as a public building or monument has also led to innovative architectural solutions, integrating new achievements in art and technology. Anticipating the current concept of Mediatecture, "as a hybridisation of architecture, urban design, media and new technology" (Huhtamo 2010, p. 20), the electronic façade appeared as part of the Modern Movement's proposal for a new monumentality. In their seminal manifesto "Nine Points on Monumentality" (1943), José Luis Sert, Fernand Léger and Sigfried Giedion envisaged how the use of new materials and techniques would enable the creation of buildings with a variable image, animated with vast surfaces which could serve to either project publicity and propaganda or "offer unexplored fields to mural painters and sculptors" (Sert, Léger and Giedion 1943, p. 30). Nevertheless, this revolutionary prospect was not immediately realised, and the full implementation of media systems in museum architecture did indeed take several decades. 
In the 1970s, the idea of the museum building as a transparent and flexible machine was to have an important breakthrough with Renzo Piano and Richard Rogers' project for the Pompidou Centre, in Paris. Along with the technological apparatus of the exposed infrastructures, the original design included a giant screen on the main façade, "displaying electronic messages about events in the centre or cultural and political news" (Puglisi 1999 , p. 5). Unfortunately, this device was soon abandoned due to both political and financial constraints, but it undoubtedly paved the way for the integration of media façades into museum buildings, especially in those devoted to contemporary arts. It is therefore no coincidence that the construction of the Pompidou Centre happened at a key moment in new media art history. Along with a radical revision of urban iconography, this huge cultural laboratory also introduced the concept of the museum as an interface, an idea that will be addressed later on in this article.

\section{THE VIRTUAL TURN: ONLINE MUSEUMS FOR DIGITAL ART}

In parallel to the development of new architectural models for contemporary art museums, advances in information and communication technologies have also led to the multiplication of purely virtual exhibition spaces. Although most of these projects have focused on the reproduction of physical collections (as happens with the Google Art Project), there is also a significant number of online museums specifically devoted to born-digital artworks, including a wide variety of formats and movements, ranging from the ground-breaking Net.Art movement of the 1990s to more recent trends. After the appearance of Web 2.0, two complementary visions coexisted in the field of online museums for digital art: on the one hand, the idea of archives or databases, independent of any architectural configuration or simulation; on the other hand, the notion of the museum as a global project, a total artwork including a virtual architectural container, as well as born-digital artistic contents.

The first option has often been promoted by leading international institutions, as part of their programmes for new media art. One of the first and most consistent experiments was Gallery 9, an online exhibition space created by Walker Art Center, under the direction of Steve Dietz, who wrote the following introduction to the project:

Gallery 9 is a site for project-driven exploration, through digitally-based media, of all things 'cyber'. This includes artist commissions, interface experiments, exhibitions, community discussion, a study collection, hyperessays, filtered links, lectures and other guerrilla raids into real space, and collaborations with other entities. (Dietz, 1998)

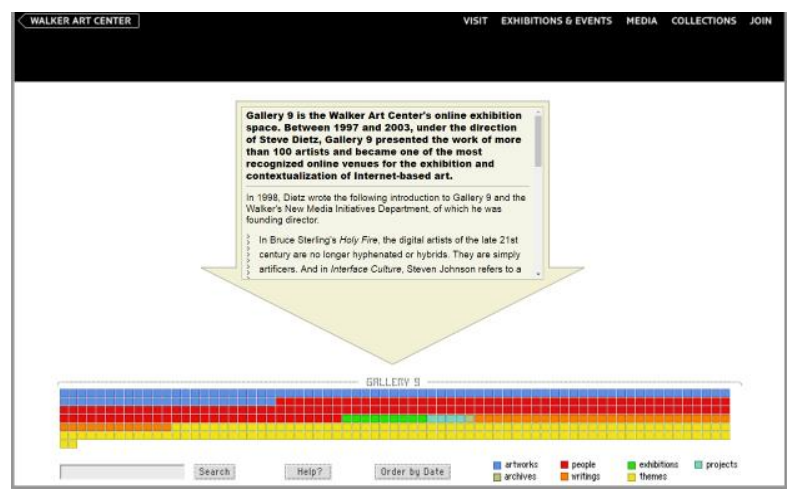

Figure 1: Gallery 9-Walker Art Center. Print screen from the gallery website http://gallery9. walkerart.org/ (retrieved 21 March 2016)

This online venue was active between 1997 and 2003, presenting the work of more than 100 artists. Besides its value as a comprehensive archive of Internet-based art, still currently accessible through the Walker Art Center's website, Gallery 9 also corresponded to a relevant contribution towards new curatorial practices, since it explored multidirectional and hyper-connected narratives that were intrinsically associated to this intangible medium. In the following years, other interesting spaces for digital art were launched on the Internet, such as DAM - Digital Art Museum (http://www.dam.org/) or Whitney Museum's Artport (http://whitney.org/Exhibitions/Artport), which has revised its interface in order to update and enlarge the resources for the production, conservation and exhibition of this type of work.

The 1990s were also a pivotal moment in terms of the second possibility, i.e. the conceptualisation of the online museum as a virtual architectural setting. This was when Roy Ascott elaborated his idea of "The Museum of the Third Kind", as a reaction to the emerging telematic culture and Internet art. The breaking point, he claimed, was "not the death of culture or the incoherence of consciousness, but the revitalisation of our whole state of being and a renewal of the conditions and construction of what we choose to call reality" (Ascott 1996). Also, at around the same time, the Guggenheim Foundation commissioned Asymptote Architecture (Hani Rashid and Lise Anne Couture) to design a cybermuseum dedicated to artworks generated exclusively within and for the Internet. Inspired by "the fusion of information space, art, commerce, and architecture", the Guggenheim Virtual Museum (1999-2002) was conceived as a navigable threedimensional object, "a new architecture of liquidity, flux, and mutability predicated on technological advances and fuelled by a basic human desire to probe the unknown" (Rashid 1999, p. 31). In fact, 
the architects designed a shape-shifting venue, which translated the instability of media art and technology into museum architecture. But was the Guggenheim Foundation, internationally recognised for its urban monuments, ready to deal with an intangible and variable iconography? Probably not. And, just a few years before the worldwide spread of the social media, neither was the general public. Nevertheless, and despite its short existence, this project provided an original perspective on museum making, paving the way for future web-based cultural buildings.

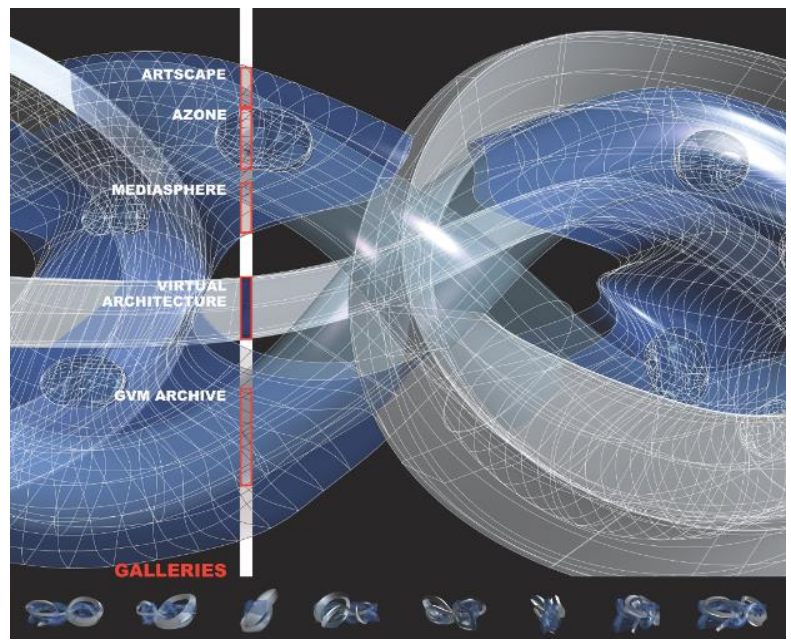

Figure 2: Asymptote Architecture, Guggenheim Virtual Museum. Courtesy of the Asymptote Architecture.

More than one decade after Asymptote's radical project, another visionary museum appeared on the web. Launched in 2010, the Adobe Museum of Digital Media was designed by a multidisciplinary team led by Filippo Innocenti, co-founder of Spin+, an open research group dedicated to the enhancement of architectural space perception through virtual environments. Adobe's objective was to create an open-access "interactive venue to present and preserve ground-breaking digital media works, inspire creative ideas and experimentation, and provide a forum for expert commentary on how digital media influences culture and society" (Adobe 2010). In spite of its apparent similarities with a real museum, this virtual building incorporated specific advantages of digital constructions: with its unlimited scale, the space was indefinitely extendable and reconfigurable, so archives could expand according to the growth of their collections and galleries could be adapted to each artist's or curator's project (Grozdanic 2011). Besides assuming that the virtual museum is, by its very nature, an everchanging space (a feature that was equally critical Asymptote's project), an interesting aspect of Adobe's temporary initiative (no longer available online) was that it dealt with matters of transference and ubiquity, foreshadowing, for example, the integration of the museum into various real urban environments.

Similar to the Guggenheim Virtual Museum, the Adobe Museum of Digital Media made only a very brief appearance on the Internet and, therefore, its mission was never completely fulfilled. Regardless of the institutional and commercial reasons behind the premature closure of these virtual venues, it is evident that purely online museums of digital art have often failed to achieve most of their aims. Interestingly, this propensity for failure is not exclusive to virtual museums, as many real venue art projects have also been abandoned shortly after winning international competitions or being awarded important architectural commissions.

\section{OVERCOMING THE PARADOX: THE MUSEUM AS INTERFACE}

In most cases, new media art collections and programmes have been integrated into modern and contemporary art centres. However, over the last two decades, a set of new museums and galleries have been specifically conceived for works of this type. Frequently, both the name and the mission of these institutions underline the connection between art and technology. Among the most remarkable, yet unbuilt projects is Rem Koolhas' proposal for the Zentrum für Kunst und Medientechnologie (ZKM), a Centre for Art and Media in Karlsruhe, Germany (1989-1991).

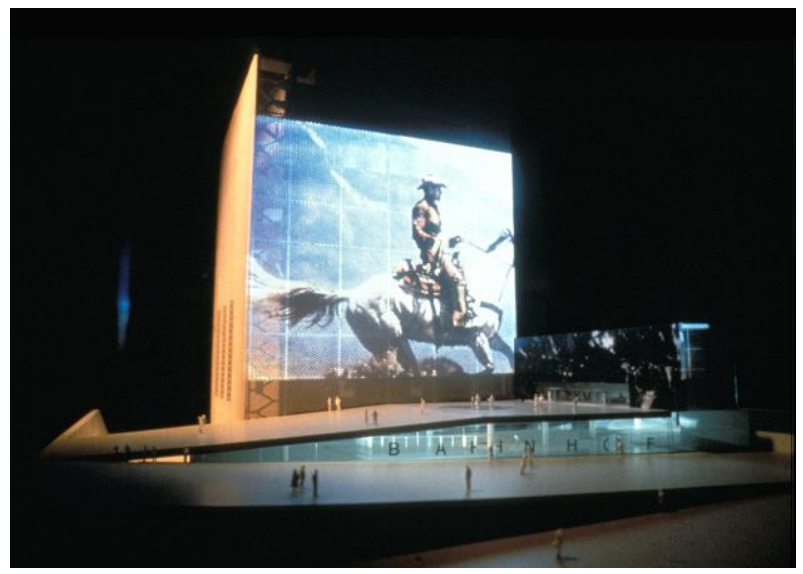

Figure 3: Rem Koolhaas/OMA, ZKM - Centre for Art and Media, Karlsruhe. Courtesy of OMA.

Here, Koolhaas revisits Piano and Rogers' idea of the cultural laboratory, combining mechanical movable elements with an electronic façade. According to the architect, ZKM was conceived as an experimental "arena where different media classical and futuristic - can compete with and influence each other" (Koolhaas 1989), a dynamic building acting as an interface of diverse contents and activities capable of generating a "hybrid condition". In this way, ZKM addresses the 
instability of a programme that is necessarily open to change, and thus indetermination and flux appear as part of the building as much as of the city itself.

Over the following years, the rapid development of communication and information technologies contributed to an increasing interest in new media art museums as an architectural programme. The eclectic situation of visual arts after the Internet also re-contextualised and updated the idea of the museum as interface. In fact, the gradual merging together of material and virtual constructions soon demanded a different approach to the museum space as a platform for diverse means of artistic production and communication.

These principles are clearly visible in the project for the Eyebeam Museum of Art and Technology in New York, designed by the architectural studio of Diller Scofidio + Renfro (2001-2004). Founded in 1997, the institution has been dedicated since then "to exposing broad and diverse audiences to emerging artistic practice critically engaged with new technology, while simultaneously acting as an educator of technology's potential for creativity" (Eyebeam 2016). Acknowledging the rapid and unpredictable evolution of media technologies, Eyebeam consists of a transparent, flexible and responsive structure where architecture and art interplay with one another through the active participation of multiple actors, including not only artists, curators and scientists, but also audiences. In this sense, the architects clearly recognise that the visitor is no longer a mere spectator, but rather a decisive element in an interactive system. As far as the dialectic between communication technology and museum building is concerned, Elizabeth Diller stressed that Eyebeam faced an open and uncharted territory:

\footnotetext{
The great challenge ahead is to reconcile their discrepancy in speed: architecture is permanent by nature and new media is transient by definition. We will have to invent the map as we navigate it." (Diller 2002).
}

Although this project was never materialised, some of its key ideas were later explored by the architects at the Institute of Contemporary Art, in Boston (2001-2006).

At the beginning of the twenty-first century, the idea of interface and hybridisation became paramount to achieving a balance between digital and material dimensions. Observing the very small number of venues effectively built for new media art, it is possible to identify a tendency to focus on the possibilities of the electronic façade, both as a symbol of the programme and as an appealing icon of the city capable of promoting a spectacular dialogue with the surrounding urban space, as happens with the new Ars Electronica Center, in Linz, Austria, designed by Treusch Architecture and opened in 2009. As Antoine Picon explains:

\begin{abstract}
In the age of the computer, the physics of solids and DNA manipulations, materiality is more and more defined at the intersection of two seemingly opposed categories, the totally abstract, based on signals and codes, on the one hand, the ultra-concrete, involving an acute and almost pathological perception of material phenomena and properties such as light and texture as they are revealed by zooming-like practices. This short-circuit between the abstract and the ultra-material is, I think, quite representative of the new world of sensations and movements that we are entering today (Picon 2003, p. 110).
\end{abstract}

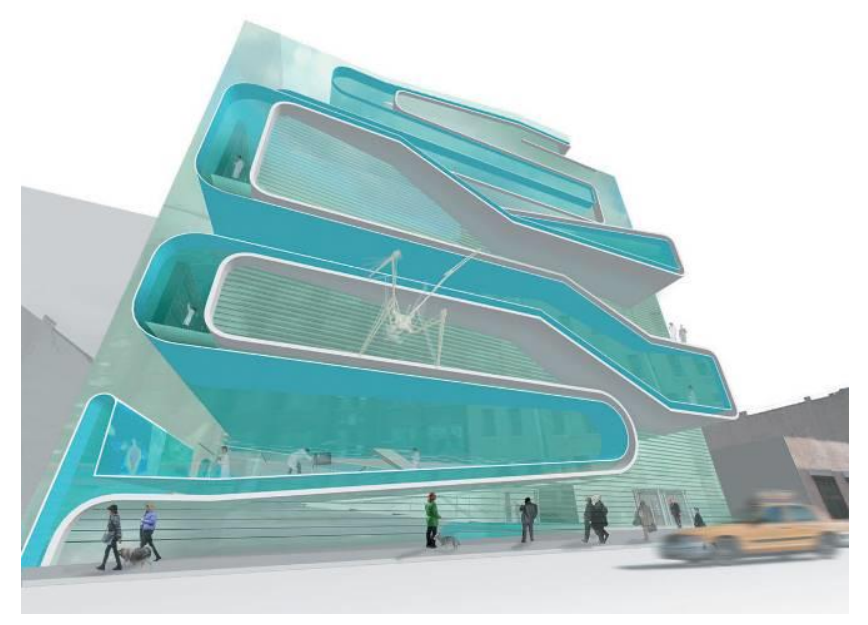

Figure 4: Diller Scofidio + Renfro, Eyebeam Museum of Art and Technology, 2001. Courtesy of Diller Scofidio + Renfro.

Unlike in real museums, the poetics of transformation and connectivity between concrete and virtual spheres has been primarily explored under the scope of independent and hypothetical projects. A recent architecture competition for a Digital Arts Museum in Madrid, received several innovative proposals, most of them produced by young architects based in different countries. Promoted by the online platform CTRL+SPACE, this competition sought "to create a museum devoted to the contemporary arts, in particular those that explore the more recent technologies as an integrated medium of work" (CTRL+SPACE 2014). Questioning "how the characteristics of Digital Art might be transposed into space, in a way that enhances a better understanding of the exhibited work", the competition brief also addressed the effects of technology on museum practice and on the public's access to culture (idem). 

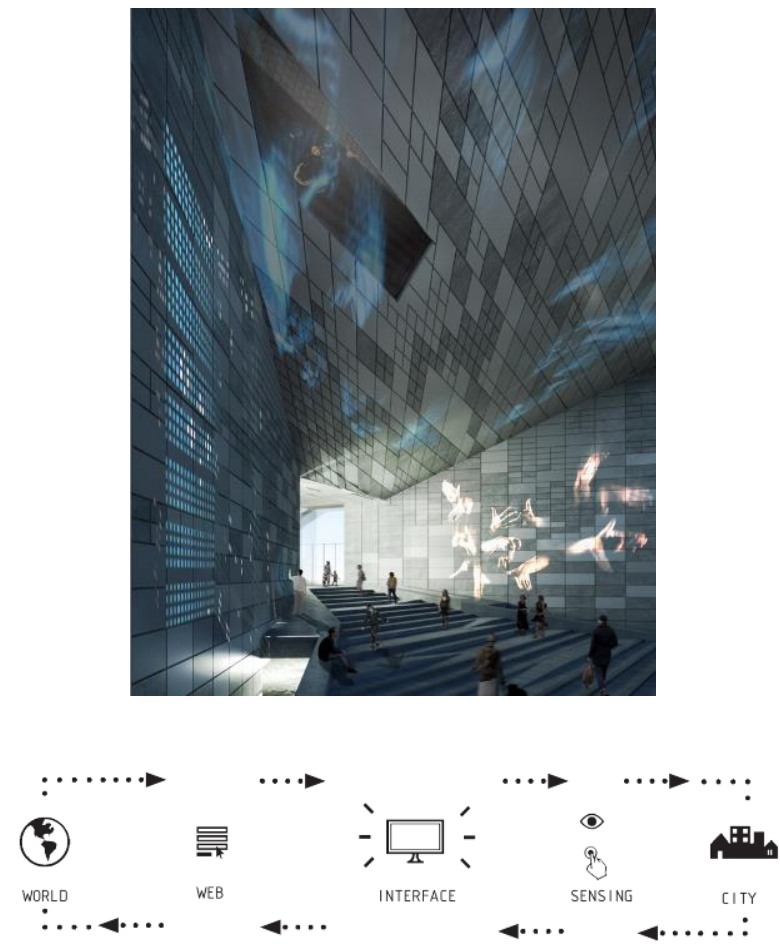

Figures 5 and 6: Michelangelo Vallicelli et al., Digital Arts Museum in Madrid (Architecture Competition - First Prize), 2014. Render and diagram illustrating the idea of the museum as interface. Courtesy of Michelangelo Vallicelli and CTRL+SPACE.

Although the programme was relatively conventional in terms of space organisation, the winning project went far beyond the immediate requirements, presenting an insightful vision of the role of a digital arts museum in present-day society. Designed by the Italian architects Michelangelo Vallicelli, Lorenzo Sant'Andrea and Nicolò Troianiello, the project reinterprets the concept of the museum as interface, since the building is conceived as a "sensing and responsive locative medium" (Vallicelli et al. 2014). Furthermore, the proposal focuses on the idea of the 'meta-museum' "which, in addition to having an online storage system, also has a web page that represents a selection of art materials and allows individuals anywhere in the world to upload and submit their own installations, video documentation [or] discussions" (idem). Those contents are then returned to the city and to the local reality of the museum (the Lavapies neighbourhood in Madrid) through the building's media façade, which can thus collect data and images from the city and distribute them through the web or vice-versa.

This interactive system, widely open to public participation, expresses today's impact of the social media on cultural practices. In this strategy, the electronic façade is not regarded merely as a surface for visual experimentation, but truly as the core element of a complex communication system that collects, stores, preserves and disseminates digital artworks, together with a wide range of other data, including the audiences' contributions and feedback. According to the architects, the façade could, for instance, "detect the greater or lesser public interest, depending on the messages or signals from electronic devices such as smartphones. In essence, the envelope is a permeable division that establishes a cycle of exchange between multiple streams" (idem).

This approach to museum architecture, situated at the crossroads of art and media technology, finally overcomes the real/virtual paradox, assuming that Post-Internet culture is, by its very nature, a hybrid and transmutable construct. As Edward Shanken notes:

In contrast to the simulations of virtual reality, responsive environments and contexts such as intelligent architecture and interactive installations tend not to create a representation that corresponds with physical reality but rather utilize real space in a way that renders it virtual and enables alternative, expanded forms of experience and reality awareness (Shanken, 2009, p. 96).

\section{CONCLUSION}

Over the last few decades, new media art and digital art museums have configured an important field for architectural research. Frequently, these projects revealed ambitious or even utopian visions that derived from profound contradictions between the promising world of information technology and the very pragmatic requirements of museum architecture. As in previous periods of art history, some of the most thought-provoking designs did not end up as finished buildings, either because their construction proved to be too expensive and technically problematical, or just because they were specifically conceived as virtual spaces. Moreover, the fact that ground-breaking projects (such as the Guggenheim Virtual Museum or the Adobe Museum of Digital Media) did not succeed as online venues confirms the idea that there is a utopian side to digital art museums which is beyond the challenges of materialisation. What, then, are the critical characteristics of these museums?

First and foremost, the instability and unpredictability of new media art itself, which necessarily demands a flexible and adaptable setting. If extensibility has historically been associated with museum architecture (at least since Le Corbusier's Museum of Unlimited Growth), then changeability now emerges as a central issue. As Hani Rashid explained:

The virtual Guggenheim museum [...] is an entire shape shifting museum. [...] It was fascinating and amazing. Unfortunately the 
world was not quite ready. I think we were a touch too fast off the mark. In ten, twenty, thirty years from now we will find more and more interaction between virtuality and reality (Rashid 2012).

Along with variability, hybridisation appears as a fundamental challenge. Web-specific museums have decisively contributed to a questioning of the specificity of programmes and spaces for digital art and, in so doing, they have suggested new approaches to the virtual/material dichotomy. As Manuel Castells pointed out very early on:

\footnotetext{
Virtual museums are more and more common, and the articulation between the real and the virtual, the physical and the symbolic is increasingly developing new cultural hybrids that generate the renewal of cultural communication in the world, using new forms of information and communications technology" (Castells 2001, p. $4)$.
}

The current convergence of virtuality and reality has favoured the concept of the museum as interface, which has inspired not only innovative (and mostly unbuilt) architectural projects, but also different museum programmes that explore the relationship between place and non-place.

Among the relatively reduced number of centres specially created to conserve and display digital art, there are interesting alternatives to the conventional idea of museum building. Founded in 1997, the Austin Museum of Digital Art (AMODA), in USA, "has no permanent physical space or venue. As a 'museum without walls', AMODA presents exhibitions, showcases, film screenings, lectures, and other events at various locations in Austin, often in collaboration with other arts and educational organizations" (AMODA 2016). More recently, the Digital Interactive Art Space (DIAS) has chosen the Vallensbæk Station, near Copenhagen, Denmark, as a platform for contemporary artistic creation and diffusion. Considering that "the station is a place without quality or substance in itself", a non-place that is normally just used to get somewhere else, DIAS "creates an opportunity to rethink the relationship between art and reality" (DIAS 2016). This curatorial approach questions the presence of art institutions in urban life, as it creates a stimulating context for diverse reinterpretations of the audience's role. Furthermore, this last example, just like several of the projects examined in this paper, illustrates the idea of the museum as a space for transit and connectivity. These qualities, intrinsically linked to the current overlapping of real life, digital media and virtual networks, definitely reshape Roy Ascott's vision of the "Museum of the Third Kind".
Assuming a permanent interaction between their physical and online interfaces, these institutions have found innovative ways of overcoming the paradox of creating a material container to preserve and display immaterial artworks. Moreover, the pervasiveness of digital communication devices also allows for different forms of participation, providing audiences with unprecedented tools not only to interpret, appropriate and recreate artworks, but also to interact with the exhibition space within and beyond the museum's physical container. Together, Internet, virtual reality, augmented reality and social media have reconfigured the transitory context where new media art venues can actually exist; being online and offline at the same time, the digital art museum has finally found its uncharted territory, between the virtual and a hard place.

\section{REFERENCES}

Adobe (2010) Adobe Launches Adobe Museum of Digital Media (Press Release Sept. 20, 2010). URL: http://www.adobe.com/aboutadobe/pressroom/pres sreleases/pdfs/201009/092010AdobeMuseumDigit alMedia.pdf (retrieved 20 March 2016).

AMODA - Austin Museum of Digital Art (2016) About AMODA. URL: http://www.amoda.org/about/ (retrieved 17 March 2016).

Barranha, H., Martins, S. S., Monteiro, R. X., and Pereira, R. (2015) How digital is the digital art museum? [poster]. In Dirim, H. A. (ed.) Urban Identity, Space Studies and Contemporary Arts Contempart'15. DAKAM - Eastern Mediterranean Academic Research Centre, Istanbul. URL: http://unplace.org/sites/default/files/How digital Ist anbul poster.pdf (retrieved 18 March 2016).

Ascott, R. (1996) The Museum of the Third Kind, InterCommunication no. 15, 1996. URL: http://www.ntticc.or.jp/pub/ic mag/ic015/ascott/asc ott e.html (retrieved 21 March 2016).

Castells, M. (2001) Museums in the Information Era: Cultural connectors of time and space. ICOM News, Special Issue vol. 54, no. 3, pp. 4-7.

CTRL+SPACE (2014) Madrid Digital Arts Museum Ideas Competition - Competition Brief [PDF]. URL: http://www.ctrl-space.net/madrid.html (retrieved 5 August 2014; the PDF file is no longer available online).

DIAS - Digital Interactive Art Space (2016) About DIAS. URL: http://diaskunsthal.dk/about/?lang=en (retrieved 24 March 2016).

Dietz, S. (1998) Gallery 9 - Walker Art Center. URL: http://gallery9.walkerart.org/ (retrieved 21 March 2016). 
Diller, E. (2002) Eyebeam. URL: http://www.arcspace.com/features/diller-scofidio-renfro/eyebeam/ (retrieved 17 March 2016).

EIA - Electronic Arts Intermix (2013). Media Art Resource. URL: http://www.eai.org/resourceguide/ (retrieved 21 March 2016).

Eyebeam (2016) Eyebeam: About - History. URL: http://eyebeam.org/about (retrieved 17 March 2016).

Grozdanic, L. (2011) Adobe Museum of Digital Media / Filippo Innocenti. eVolo Journal online, Oct. 31, 2011 URL:

http://www.evolo.us/architecture/adobe-museumof-digital-media-filippo-innocenti/ $\quad$ (retrieved 21 March 2016).

Huhtamo, E. (2010) Pre-envisioning Mediatecture: A Media-archaeological Perspective. In Kronhagel, C. (ed.) Mediatecture - The Design of Medially Augmented Spaces. Springer, Vienna.

Koolhaas, R. / OMA - Office for Metropolitan Architecture (1989) Zentrum fur Kunst und Medientechnologie. URL: http://oma.eu/projects/zentrum-fur-kunst-undmedientechnologie (retrieved 18 March 2012).

Olson, M. (2011) Postinternet: Art after the Internet. In McNeil, J. and Quaranta, D. (2014) Art and the Internet. London: Black Dog Publishing.

Paul, C. (2002) Renderings of Digital Art. Leonardo, vol. 35, no. 5, Tenth Anniversary New York Digital Salon (2002), pp. 471-474. URL: http://www.jstor.org/stable/1577254 (retrieved 17 March 2012).

Picon, A. (2003) Architecture and the Virtual Towards a new Materiality? Thesis Wissenschaftliche Zeitschrift der BauhausUniversität Weimar, no. 3, pp. 107-111.
Puglisi, L. P. (1999) Hyper Architecture: Space in the electronic age. Birkhäuser, Basel (original version in Italian, 1998).

Rashid, H. (2012) Interview by Norman Kietzmann Kietzmann, Hani Rashid / Asymptote. Crystal Talk. URL:

http://www.baunetz.de/talk/crystal/index.php?lang= en\&cat=Profil\&nr=17 (retrieved 16 March 2016).

Rashid, H. (1999) The Museum as a Digital Experience. In Proceedings of the ICOMON meetings held in Madrid, Spain, 1999 (2001) Museo Casa de la Moneda, Madrid.

Sert, J. L., Léger, F., and Giedion, S. (1943) Nine Points on Monumentality. In Ockman, J. (1993) Architecture Culture 1943-1968: A Documentary Anthology. Columbia University, New York.

Shanken, E. A. (2009) Art and Electronic Media. Phaidon, London.

Tate (2000) Between Cinema and a Hard Place. URL: http://www.tate.org.uk/whats-on/tatemodern/exhibition/between-cinema-and-hard-place (retrieved 17 March 2012).

Vallicelli, M., Sant'Andrea, L., and Troianiello, N. (2014) Urban Interface - A Meta-Museum for Digital Arts. Madrid Digital Arts Museum Ideas Competition (unpublished - courtesy of Michelangelo Vallicelli and CTRL+SPACE).

\section{ACKNOWLEDGEMENTS}

Asymptote Architecture CTRL+SPACE Diller Scofidio + Renfro Isabella Rossen John Elliott Julianne Jones Michelangelo Vallicelli OMA

Vicente Spínola 